\title{
Classroom Quality: On the Amount of Ambient Light in Today's Classroom - A Field Study
}

\author{
Christian Schuss and Tapio Fabritius \\ Optoelectronics and Measurement Techniques (OPEM) Research Unit, University of Oulu, Finland; \\ email: christian.schuss, tapio.fabritius@oulu.fi
}

\begin{abstract}
In this paper, we investigate the given ambient lighting conditions in today's schools. On the example of Oulu University Teacher Training School, the classroom quality in terms of the available amount of ambient lighting is analysed. In particular, attention is paid to the available illuminance of the pupils' desks. Commonly, light is produced artificially by light sources installed on the classroom's ceiling and obtained from the outside through windows. However, due to the use of digital blackboards, window blinds are often closed and lights are often switched off, thereby, reducing the available light in the classroom significantly. Furthermore, our results reveal that each pupil's desk receives a different light intensity. It is worth noting that low levels of ambient lighting can result into a degradation of learning performances and, therefore, requiring pupils more time solve different types of activities assigned by the teacher.

Index Terms-ambient light, concentration, illumination, learning environment, light intensity, measurement, productivity, school, study environment.
\end{abstract}

\section{INTRODUCTION}

Nowadays, in primary and secondary schools, classrooms often remind us still on traditional classrooms which we already had decades ago. While open learning environments have gained increased interest over the recent years, in the majority of schools, the layout of the classroom still follows the traditional layout. In other words, the teacher having a desk in the front of the classroom, next to the blackboard, and all the pupils sitting in front of the teacher's desk. Figs. 1-3 show examples for classrooms at the Oulu University Teacher Training School. The configuration of the pupils' desks can slightly differ, however, the basic configuration for lectures such as mathematics, languages, history, religion, to name a few, remains the same.

In the available literature, extensive analyses on the classroom quality by various researchers in terms of different aspects can be found. Similar to the learning outcomes of pupils in the classroom, in office spaces, the productivity and efficiency of workers is affected by ambient conditions. Even though individual aspects can differ for example due to different activities of workers and pupils, some of the main aspects remain the same. In the focus is the personal wellbeing of the individual which is affected by the conditions of the surrounding environment.

Depending on the field of research, analysing the conditions of the classroom in order to determine the classroom quality can be done in different ways. Tabuchi et al. analyse in their work the physical setup of the classroom, for example, the location and position of light sources within indoor locations [1].

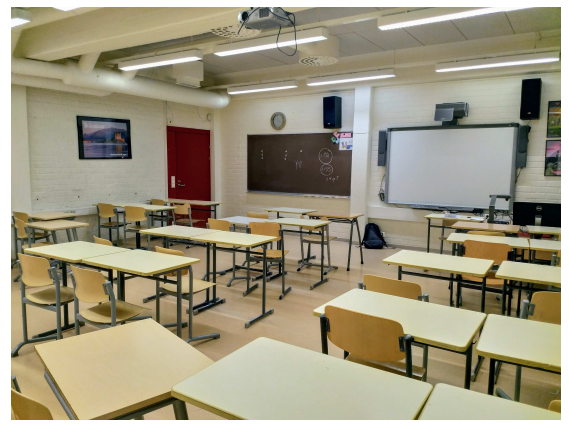

Fig. 1: Example for conditions: Classroom A

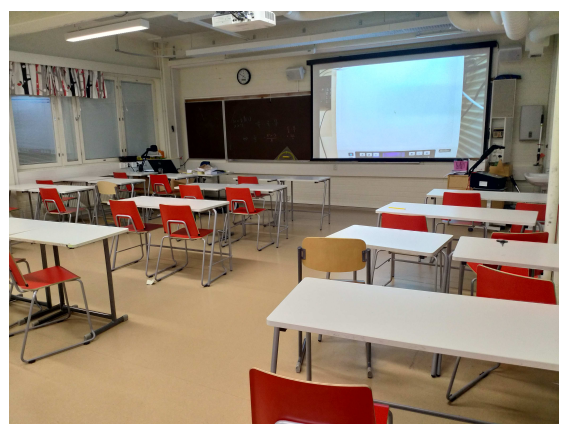

Fig. 2: Example for conditions: Classroom B

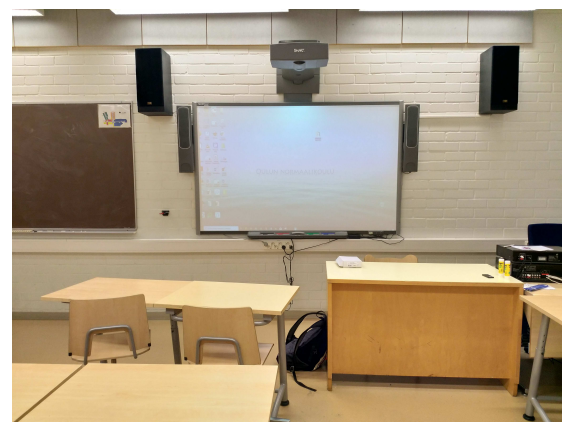

Fig. 3: Example for conditions: Classroom C

The characteristics of the indoor environment are described from an architectural point of view. In [1], the light sources on the ceiling are very well aligned with work desks, in other words the furniture underneath. Hence, it can be said that the available light from lamps can be used in an optimised way for the working surfaces underneath the lamps. 
Fielding describes the available light in indoor environments as a combination of light produced inside the indoor environment and light received from outside the indoor environment [2]. As in [1], Fielding state that the available illuminance of surfaces such as workers' and pupils' desks is affected by the reflection coefficient of walls. Fielding discusses on the impact of the room's ceiling and floor in receiving light from outside the indoor environment. Furthermore, Fielding elaborates how light affects the pupil's wellbeing and capability of learning and studying. Different individuals have different criteria but the same overall goal as feeling comfortable within their environment [2].

\section{BACKGROUND AND RELATED RESEARCH}

\section{A. The Importance of the Learning Environment}

Fielding also emphasises that the learning environment of the $21^{\text {th }}$ century has little in common with the traditional classroom. The design of a fruitful and inspiring learning environment is started by the layout of the building within the given landscape. Regarding the learning environment, Fielding also concentrates on aspects which unconsciously affect people. The outdoor environment is not only an additional light source, but also offers a form of relaxation. In particular when sitting next to a window, individuals often look up and out without an apparent goal in mind. People do so to rest their eyes by changing the focal length which results in a form of relaxation for the eyes, away from a narrow point of view.

Fielding points out the design not only affects the available distribution of light and colour within a space, but also how the human eye and, thus, the human body is lead through a space [2]. The available light and its distribution within the given space affects the perception of the space by humans. The light intensity should be variable addressing different learning preferences and different learning times. Furthermore, the available light from indoor light sources in regard to the spectrum should match the daylight spectrum as good as possible.

\section{B. The Illuminance of Surfaces}

It is crucial to have high illuminances on surfaces where light is needed, such as the pupils' desk. In [2], it is mentioned that the design of the learning environment also affects the willingness and motivation of pupils to collaborate on assignments and, thus, in the capability of developing soft skills. Reimers et al. highlight in their work that soft skills are especially needed in future jobs as such skills cannot be replicated in an easy way by machines, computers or artificial intelligence [3].

Fielding recommends learning from the past and avoid mistakes made in designing future learning environments [2]. For example, uniform lighting makes sense in assembly line production, but not in a learning environment focusing on the encouragement and creation of creative and innovative thinking. Moreover, often, children are sensitive to the light intensity and light spectrum, affecting their biorhythm, for example. Fielding states that it is falsely assumed that natural light is difficult to control and, thus, shut out from the room by closing the window blends. However, according to [2], it is perhaps the single-most important element in the learning environment. Research showed in classrooms in which daylight is present, math scores improve by $20 \%$ and verbal scores by $22 \%$ [2].

\section{The Situation IN TOdAY's ClassRooms}

\section{A. The Floorplan of Classrooms}

In the typical floor plan of a classroom as described in [4], fluorescent lighting sources are oriented parallel to windows for front classroom focus. With the help of this layout, the goal is to provide an equal amount of ambient lighting on top of all surfaces in the classroom. According to [4], this approach is considered not to be ideal for supporting learning activities. In the layout and placement of light sources follows a indirect/direct fixture running parallel to the windows. As suggested in [4], this layout is suitable to provide an even ambient lighting level. With the help of recessed accent lighting, in the front of the classroom, the required light intensity of about 1,000 lx can be provided.

\section{B. The Required Amount of Light in Classrooms}

As in [4], different types of light sources and fixtures are used to create the appropriate light quality and, thereby, the desired classroom quality. In [4], light quality is defined as visual comfort, good colour, uniformity and balanced brightness. The setup of the light sources and distribution of the light in the classroom depends also on the purpose and types of activities in the classroom. In addition, it is possible to improve the readability of the information displayed on the digital blackboard. As a result, the pupils' attention can be caught and kept during the lecture.

According to [5], the preferable light intensity is $570 \mathrm{~lx}$, which is perceived as the standard classroom light intensity. White points out that the wrong light intensity and light spectrum, for example coming from cool-white fluorescent light sources can cause more physiologically arousing, and, furthermore, increase the hyperactive behaviour of children already prone to autism and other psychological disturbances [5]. Lage et al. emphase in their work that not only the quality of the learning environment affects the pupils' performance, but also the teachers', in other words, the instructors' performance [6].

\section{Background of the School in Experiments}

All experiments in this work were conducted at Oulu University Teacher Training School in the city district Linnanmaa of the City of Oulu, Finland. The school was established about 30 years ago. At that time, digital blackboards were not available. Hence, the layout of the classroom as well as the school itself were designed in a typical traditional matter. Later on, with the increase in interest in digital blackboards, one traditional blackboard was exchanged with a digital blackboard and a personal computer (PC) was added to the teacher's desk. 
However, the age of the school does not have necessarily an impact on the quality of the learning environment [7]. Spatial configurations, noise, heat, cold, light, and air quality affect teachers' and students' abilities to perform. According to [7], in the US, in some cases, buildings constructed as civic monuments in the 1920 and 1930s still provide a suitable learning environment, but buildings erected in the cost-conscious, costcutting 1960s and 1970s do not. Costs did not only affect the construction of the school, but also play a role in the maintenance of a school. For example, light sources are chosen in such a way that energy can be conserved and, thus, running costs can be reduced.

\section{Results of the Field Tests}

\section{A. Purpose of Measurements}

In this work, the decision was made to obtain measurement results with the help of portable light spectrum meters. Alternatively, the light intensity could also be obtained with ambient light sensors (ALS) within smartphones or interfaced with smartphones for example through near field communication (NFC) [8]-[10]. Generally speaking, it can be challenging for humans to determine the exact light intensity. If questionaries would be used as a research method, the spread of results could be wide as each individual person can have a different perception of the light intensity and the brightness of the light.

In order to obtain comparable results from different classrooms, for the collection of the measurements, two colour spectrum analysers of the type RGBW200 from the company ELV were used. This type of colour spectrum analyser features a Vishay sensor to obtain the light intensity and spectrum of the light in a 16-bit resolution. The range of the measurement instrument ranges from $0.01 \mathrm{~lx}$ up to $118,000 \mathrm{~lx}$, divided into 6 measurement intervals, allowing to carry out measurements, both, under indoor and outdoor environmental conditions. The purpose of the measurements was to determine the available illuminances on top of the pupils' desk and to compare the obtained results with the suggestions in the available literature.

As discussed in the available literature, recommendations are made to have $570 \mathrm{~lx}$ available to provide good conditions for pupils, for example, for reading their textbooks or for solving exercises in their textbooks. Measurements were collected in the centre of the pupil's desk. In this research work, the focus lies on the available light intensity, in order words the available illuminance of the pupil's desk's surface, even though the ELV RGBW200 is capable of obtaining the spectrum of the light at the same time with the measurement of the light intensity. Measurement data is presented directly on the display of the measurement instrument and can also be logged to the internal memory and transferred then later for analyses to a personal computer.

\section{B. Duration of Measurements}

Measurements were collected in two different ways. Firstly, measurements were collected directly after a class at each desk in order to determine the illuminance which each pupil had on his/her desk. Commonly, windows blinds were dimmed, allowing no light (i.e. daylight) from outside. This situation was properly the case to improve the readability of the digital blackboard. Similarly, the front light is usually switched off to make it easier for pupils to read the information shown on the digital blackboard. As shown in Fig. 3, with the front light turned on, the readability of the digital blackboard is poor.

However, as discussed in the available literature, it is highly beneficial that pupils are exposed to daylight at school. If the window blinds are closed, then, unfortunately, no contribution from the outside is made to the available ambient lighting in the classroom. As a result, all available light in the classroom comes solely from the light sources installed on the ceiling of the classroom. The available light from outside the classroom depends on the time of the day and the time of the year as well as the orientation of the classroom towards the sun. Still, without the window blinds open, the contribution of the daylight to the overall available ambient lighting in the classroom is neglectable.

Secondly, the available light intensity was measured during classes. It is worth noting that even though nowadays the digital blackboard is an important tool for the teacher, teacher do not depend the entire class on the digital blackboard. Sometimes, activities are carried out which do not require the digital blackboard. It is worth noting that the light switches are located on average about 10 metres away from the teacher's desk and cannot be controlled remotely. However, when activites last for 10 up to 20 minutes or even longer, then, the teacher could make the effort to adjust the ambient lighting in the classroom based on the requirements of the given activity.

\section{Measurement Results}

The following figures present the measurement results carried out within field tests at the Oulu University Teacher Training School. The figures were created with the help of MATLAB in which the obtained light intensities were related with a colour scale. For the comparison of the three different classrooms, the maximum of the scale was fixed to $800 \mathrm{~lx}$. As seen Figs. 4-9, some spots are black as there are no seats for pupils available or seats which are normally not used by pupils. Figs. 4 and 5 show the circumstances in classroom A. As seen in Figs. 4 and 5, on top of none of the pupils' desk 570 lx was obtained. At full lighting, the highest available light intensity is observed in the last row of the classroom.

Sitting in the first row and, therefore, in front of the digital blackboard can make it easier for pupils to read the information shown on the digital blackboard. However, as seen in Fig. 5, sitting in the first row results in a significantly lower light intensity in comparison to other locations in the classroom. Based on these circumstances, it can be difficult for teachers to assign spots for pupils in the classroom. If pupils have reading difficulties, then it will help these kinds of pupils, when teachers place them in the first row of the classroom. However, this statement is only true for reading information from the digital blackboard, but not for information in the textbooks lying in front of the pupils. If the ambient lighting conditions in the classroom remain constant throughout the 


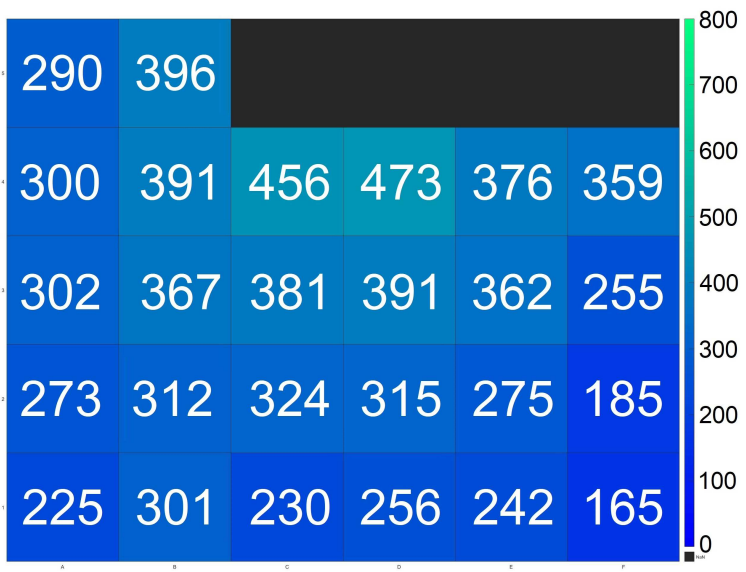

Fig. 4: Measurement 1: Classroom A, front light on

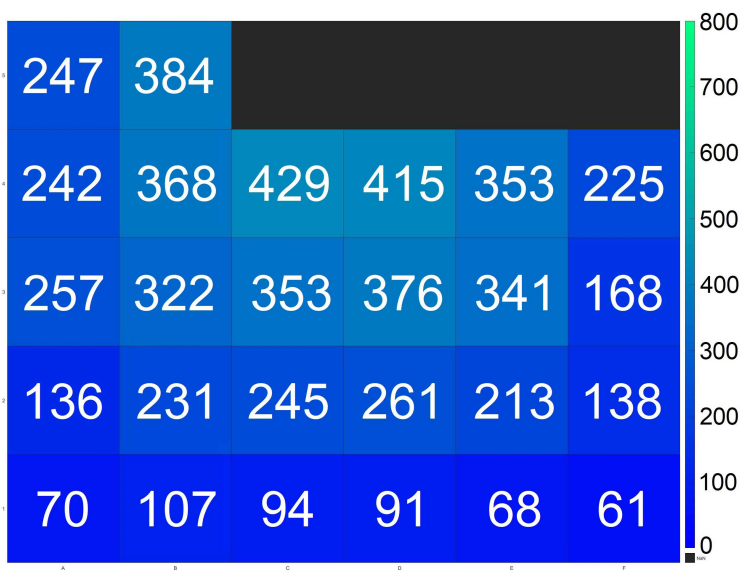

Fig. 5: Measurement 2: Classroom A, front light off

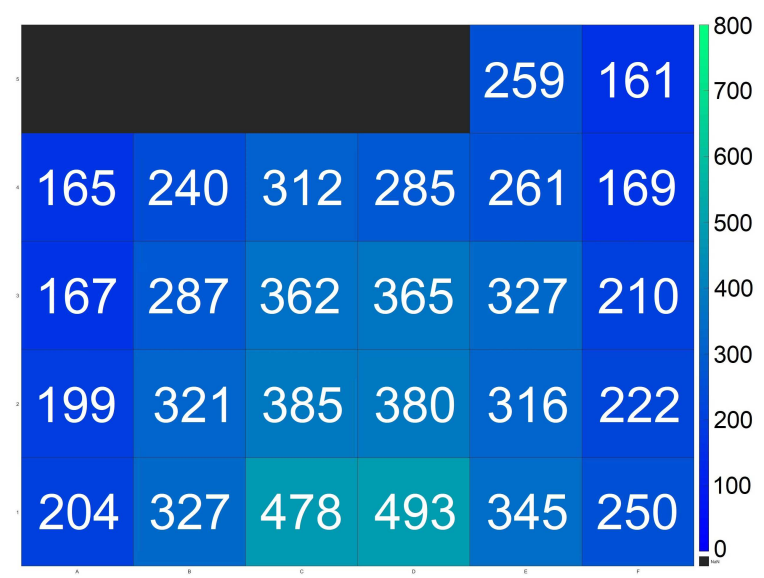

Fig. 6: Measurement 3: Classroom B, front light on

class, then it would be the pupils' sitting locations which would need to be altered during the class.

Figs. 6 and 7 show the available ambient lighting in the classroom B. This particular classroom is properly the classroom with the lowest light intensity available at Oulu University Teacher Training School. As seen in Fig. 6, like in

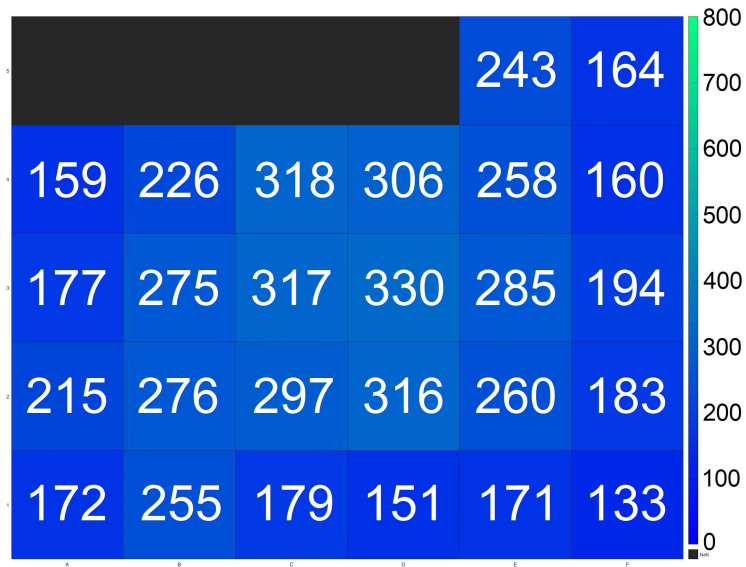

Fig. 7: Measurement 4: Classroom B, front light off

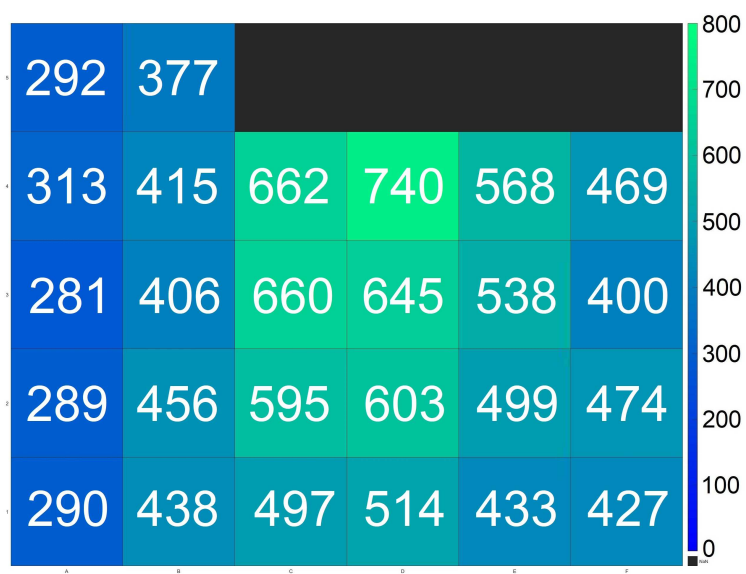

Fig. 8: Measurement 5: Classroom C, front light on

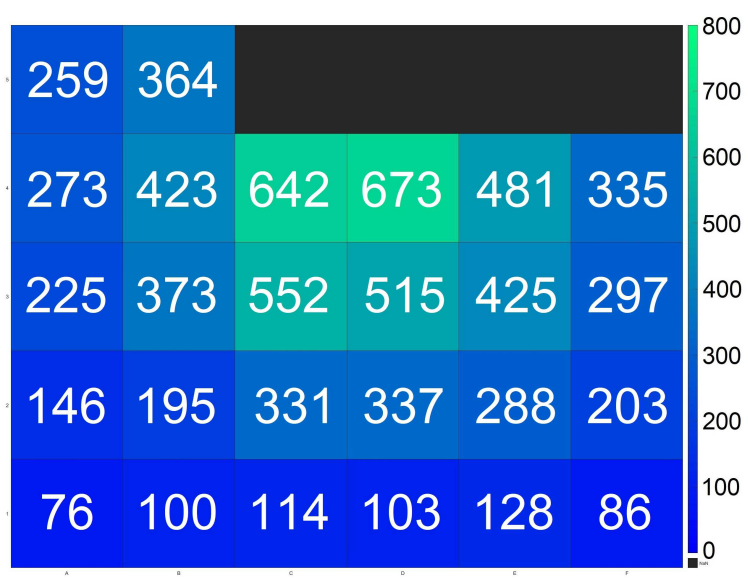

Fig. 9: Measurement 6: Classroom C, front light off

classroom B, even at full lighting from the light sources on the ceiling of the classroom, at none of the pupils' desks, 570 lx can be achieved. Only in the first row, in front of the digital blackboard, on two desks about 480-490 lx can be obtained. However, this amount is quickly reduced, when teachers turn off the front light due to the rather old projector available 
in the classroom. As a result, as seen in Fig. 7, some pupils receive less than one third of the recommended light intensity.

With such circumstances in terms of available ambient lighting present in the classroom, it can be stated that without the support of daylight, in other words, additional light coming from outside the classroom, the recommended light intensity of $570 \mathrm{~lx}$ cannot be achieved in any possible way. As discussed in the available literature, such circumstances can have a significant impact on the pupils' health and wellbeing as well as on their learning performances during classes. Due to the low light intensity, as obtained within the measurements, unfortunately, it can be assumed that the available light intensity in the classroom is not suitable high enough to sufficiently and effectively support pupils in their tasks and activities carried out by the teacher [11].

Fig. 8 shows the available illuminances on the pupils' desks with full lighting in classroom $\mathrm{C}$. Even though the circumstances are better than in classroom A and $\mathrm{B}$, as seen in Fig. 8, next to window on the left-hand side and as well in front of the teacher's desk, the light intensity is very low. In contrast, on the right-hand side, the light intensity is slightly higher due to some reflections of light from the wall. The highest light intensity can be found in the middle of the classroom. However, as seen in Fig. 8, even with the maximum possible lighting from the light sources on the ceiling, the recommended $570 \mathrm{~lx}$ cannot be achieved on top of every desk in the classroom. In the middle of the classroom, the recommended light intensity is achieved and even exceeded, but on the majority of desks, the light intensity is below the recommended threshold.

Fig. 9 shows the amount of light if the front light is turned off by the teacher. When comparing Figs. 8 and 9 with each other, it can be seen that switching off the front lights not only affects the front row, but also partly the last row of desks in the classroom. As seen in Fig. 9, after switching off the front light, only two desks remain in which an illuminance equal or higher than $570 \mathrm{~lx}$ can be obtained.

Fig. 10 shows the light intensity, obtained on top of the teacher's desk, during one class. The class was held in classroom A. As seen in Fig. 10, in the beginning of the class, the window blinds were closed, and all lights were switched on. Thus, the ambient light conditions are the same as seen in Fig. 4. A bit after 14:30, the class started, and the pupils entered the classroom. The first task which the teacher prepared for the pupils was a short written exam. The teacher displayed the instructions on the digital blackboard. Around 14:35, the teacher noticed that the pupils have difficulties reading the instructions from the digital blackboard and, thus, switched off the front light. As a result, the ambient lighting conditions changed to the conditions seen in Fig. 5.

Even though every pupil has read the instructions about 10 minutes into the exam, the teacher did not turn off the digital blackboard and back on the front lighting. Likewise, after the exam, when the teacher carried out a discussion exercise with the help of the course book and without the support of the digital blackboard, the teacher did not change the ambient light

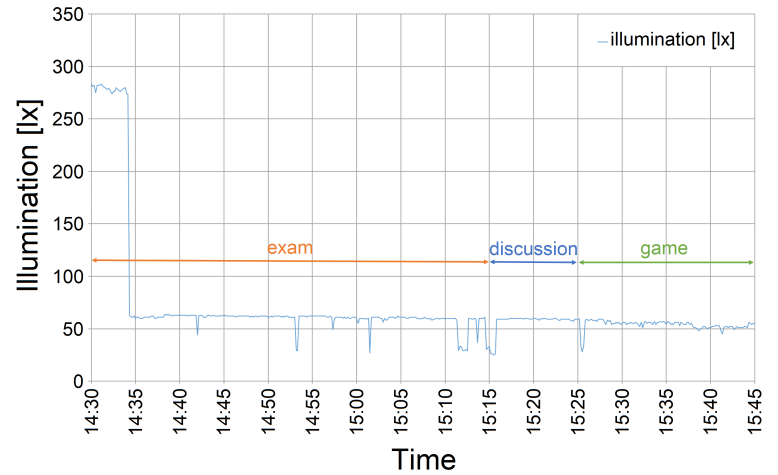

Fig. 10: Measurement 7: Classroom A, during a class

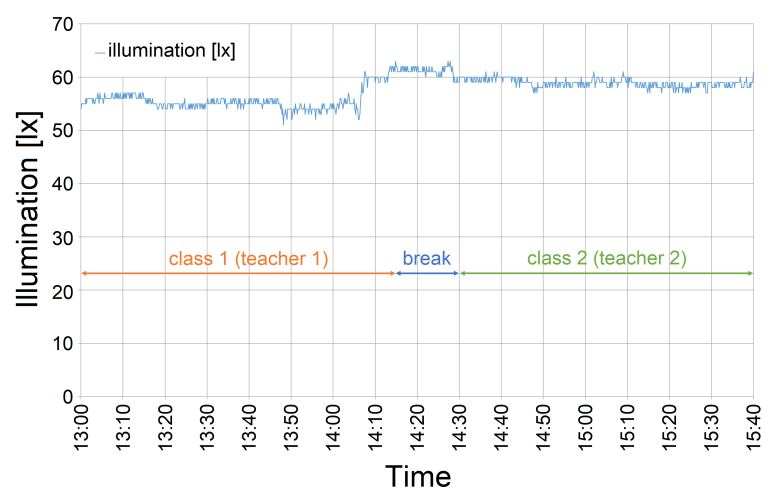

Fig. 11: Measurement 8: Classroom A, during two classes

conditions. Also, for the last activity of the class, in which the teacher has prepared a memory game and the support of the digital blackboard was not needed, the teacher did not switch back on the front lighting in the classroom. As discussed in the available literature, the outcomes of learning activities as well as the results obtained from exams can be significantly improved, if the pupils are exposed to a suitable high amount of ambient lighting. In the same way, if pupils are working under a too low level of light intensity, pupils' performance can be affected and decrease notable.

Fig 11 presents another measurement in classroom A. In this measurement, two classes are observed including the break in between the two classes. The first teacher entered the classroom, about 5 minutes prior to the start of the class at 13:00. The teacher quickly set up the exercises on the digital blackboard and checked if the audio and the video material, which are needed for the class, works properly. Even though some of the activities carried out by the first teacher (i.e. teacher 1) involved the digital blackboard, not all off the activities required the usage of the digital blackboards. Hence, it would have been possible to change the ambient lighting conditions in the classroom. However, as seen in Fig. 11, the teacher did not change switch on the front lights and, thus, the pupils were working throughout the first class (i.e. class 1) under a low light intensity, as seen in Fig. 5.

After class 1, which lasted from 13:00 to 14:15, there was a 15 minutes break, and teacher 2 took over the classroom. 
Similar to teacher 1 , teacher 2 entered the room about 5 minutes prioir to the start of the class. Also, similar to teacher 1 , teacher 2 focused on setting up the computer for the class. For example, the teacher has prepared an online quiz game for the beginning of the class. It is worth noting that every task, for example opening and preparing the online learning material, testing audio and video files, opening and preparing an online quiz game, and so on, takes a few minutes. As a result, with the available time at hands, the teacher is rather busy in preparing, configuring and testing everything before the start of the class. Thus, it could be the case that teachers, like teacher 1 and teacher 2, do not have the time to check the ambient lighting conditions in the classroom.

Teacher 1 left the room with the front lights off. Teacher 2 entered the classroom with the front lights off, as seen in Fig. 11 and did not switch on the front lights when passing by the light switches next to the classroom's door. Similar to teacher 1 , teacher 2 did not change the ambient light conditions, for example during the activities which did not require the presence/usage of the digital blackboard. As a result, the available light in the classroom is not sufficiently high enough to meet the recommended standards. Quite the opposite, the available light at some pupils' desk is only about $10 \%$ of the recommendations found in the available literature.

\section{Discussion AND CONCLUSION}

In the available literature, the importance of ambient lighting in classrooms is emphasised. Research shows that pupils show better learning performances and exam results if they are working under ambient light conditions which support different types of activities in the classroom. Recommendations are suggesting a light intensity of $570 \mathrm{~lx}$ on pupils' desks. Various factors can affect the available amount of light in the classroom. From the orientation and layout of a pupil's desk, to the reflection of light by the ceiling, the floor and walls, to the placement of lights on the ceiling, it can be said that there are various opportunities to improve and optimise the ambient light conditions.

In classrooms, teachers have not always the most optimal situation as light switches can be dislocated from the teacher's desk. Due to the age of the school and uneven aligned light sources on top of the classroom's ceiling, as seen in Figs. 1 and 2 , the given light intensity can be not high enough in every location in which desks for pupils are available. Likewise, the distance between pupils' desks in uneven. The row behind is about one metre, while the row to the side ranges two to three metres. As a result, some pupils are exposed to much more light than other pupils. Hence, it is advisable that teachers utilise light meters in order to better understand the ambient lighting conditions in their classrooms.

Nowadays, the digital blackboard is a standard tool for teachers and various exercises and activities can be carried out in the classroom with the help of the digital blackboard. However, often, as seen also in the field tests and measurements of this research work, teachers change the ambient lighting based on the usage of the digital blackboard. Window blinds are closed to avoid reflections of the digital blackboard caused by sunlight/daylight and the front light is turned off. As seen in the measurements, these circumstances reduce the available illuminance obtained on every desk of every pupil in the classroom. In particular in classrooms, in which the available amount of light intensity is already lower than the recommended standard, the conditions are deteriorated further and on top of some pupils' desk, only about $10 \%$ of the recommended light intensity is available.

It is worth noting that teachers do not require always the support of the digital blackboard. Still, teacher carry out rather traditional activities like solving an exercise in the coursebook or a group/pair work in which pupils are discussing a particular topic between them. During such activities, the digital blackboard is left in ideal and unused. Thus, teachers would have the opportunity to switch back on the front lights and also open window blinds to improve the ambient light conditions in the classroom. Doing so would help and improve the pupils' learning performances as wells as their personal health and wellbeing, as pointed out by Fielding in the available literature.

\section{ACKNOWLEDGMENT}

Dr. Christian Schuss was funded by the Academy of Finland 6Genesis (6G) project (grant no. 318927). Prof. Tapio Fabritius is partially supported by Academy of Finlands FIRI funding (grant no. 320017).

\section{REFERENCES}

[1] Y. Tabuchi, K. Matsushima, and H. Nakamura, "Preferred illuminances on surrounding surfaces in relation to task illuminance in office room using task-ambient lighting”, Journal of Light \& Visual Environment, vol. 19, no. 1, pp. 1_28-1_39, 1995.

[2] R. Fielding, "Learning, Lighting and Color: Lighting Design for Schools and Universities in the 21st Century", DesignShare (NJ1), 2006.

[3] F. Reimers, E. Bullrich, B. Cardozo, D. Edwards, S. Giannini, V. Goyal, J. Kahura, J. Lavonen, V. Pota, L. Rusha, and O.S. Tan, Connecting the dots to build the future teaching and learning, London: Varkey Education Foundation, 2016.

[4] A.S. Pulay, Awareness of daylighting on student learning in an educational facility, University of Nebraska -Lincoln, Lincoln, 2010.

[5] J.R. White, Didactic daylight design for education, State University of New York at Buffalo, 2009.

[6] M.J. Lage, G.J. Platt, and M. Treglia, "Inverting the classroom: A gateway to creating an inclusive learning environment", The Journal of Economic Education, vol. 31, no. 1, pp. 30-43, 2000.

[7] M.E. Bishop, A case study on facility design: The impact of new high school facilities in Virginia on student achievement and staff attitudes and behaviors, Doctoral dissertation, The George Washington University, 2009.

[8] C. Schuss, J. Huikari, T. Leikanger, B. Eichberger, and T. Rahkonen, "Evaluating ambient conditions for solar chargers with the help of sensors on smartphones", Proceedings of the International Instrumentation and Measurement Technology Conference (I2MTC), pp. 103-108, 2015.

[9] T. Leikanger, C. Schuss, and J. Häkkinen, "Calibration of smartphone light sensors with a near field communication enabled reference", IEEE Sensors, pp. 1-3, 2016.

[10] C. Schuss, T. Leikanger, and J. Häkkinen, "Efficient external sensors for smartphones through near field communication (NFC)", Proceedings of the IEEE International Instrumentation and Measurement Technology Conference (I2MTC), pp. 1-6, 2018.

[11] J. Salminen, The teacher as a source of educational support: exploring teacher-child interactions and teachers' pedagogical practices in Finnish preschool classrooms, Jyväskylä studies in education, psychology and social research, no. 512, 2014. 